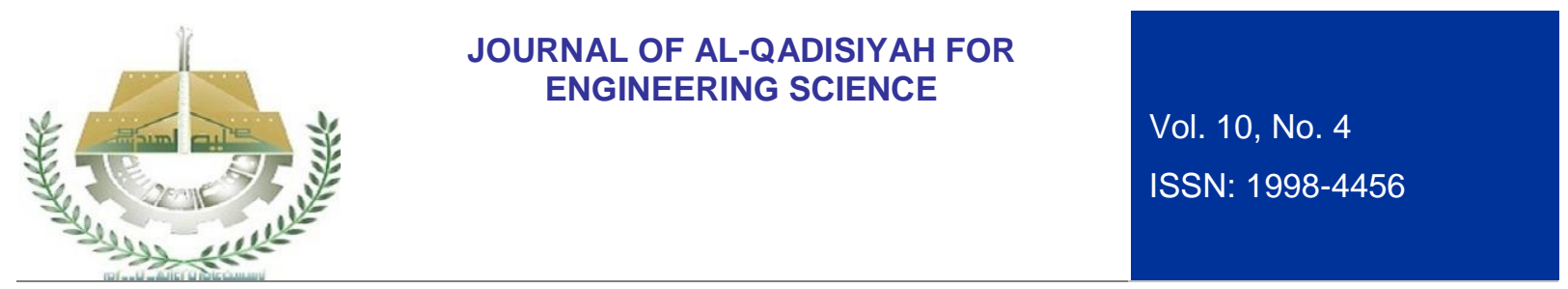

\title{
RESPONSE ENHANCEMENT OF DC MOTOR USING EVOLUTIONARY INTELLIGENT FRACTIONAL-ORDER PID CONTROLLER
}

\author{
Mr. Nasser Ali Hasson Al-Zubaydi, \\ AL-Mussaib Technical Institute, Al-Furat Al-Awsat Technical University, Babil, Iraq. \\ E-mail: nasseralzubaidy192@gmail.com
}

Received on 13 November 2017 Accepted on 13 December 2017 Published on 15 March 2018

DOI: 10.30772/qjes.v10i4.514

\begin{abstract}
An effective intelligent controller is suggested by mixing the Fractional-Order PID (FOPID) and fast genetic algorithms (FGAs) to improve the output response of DC motor. This controller is named as FGA-FOPID controller, the classical FOPID controllers have numerous benefits in practical implementation of many systems such as $D C$ motor control compared with classical PID controllers, where the output response of the DC motor with FOPID or with classical PID is reasonable, but it's not satisfaysthe response enhancements. So FGAs is used to slove the problem and to improve the overall output. The suggested work is confirmed by DC motor control system, and then compared with the classical PID and FOPID controllers. The simulated results establish that, the suggested work is adeptness from previous work.
\end{abstract}

Keywords: DC motor, PID, FOPID, Intelligent controller, Fast Genetic Algorithm.

\section{INTRODUCTION}

FOPID is complex model for PID system and needs more tuning of the parameters than classical PID controller, the tuning parameters of the FOPID controller $(P I \lambda D \mu)$ controller is very hard to achieve [1]. The idea of this system has entered into many arenas of operative means for scientific field. Numerous real schemes with the fractional variance balances which label the characteristics better. In current years, FOPID anxieties additional and many academics [2]. [1] defines and growth procedure of some fractional order controller types. [3] describe The PID of the model experiment consequences show the FOPID has strong strength. [4] determin very simple system to implemnt defferent types of PID systems. [5] explain FOPID system for speed system design. The academics and resercher study different systems to integer and progress the control and genuineness in a diversity of actual schemes, this system is more precisely than the integer system also delivers a respectable tool for the account of procedure, FOPID system is signify and better from previouse systems.

This paper is ordered as follows: the model of DC motor is explained section two, section three offers the proposed work, in section four, the simulation results are explained, and finally, the conclusions and suggestions for future work are demonstrated in section five. 


\section{DC MOTOR MODEL}

The DC motor is public and famous device in modern electrical power system. The model of the system is explained in in figure 1.

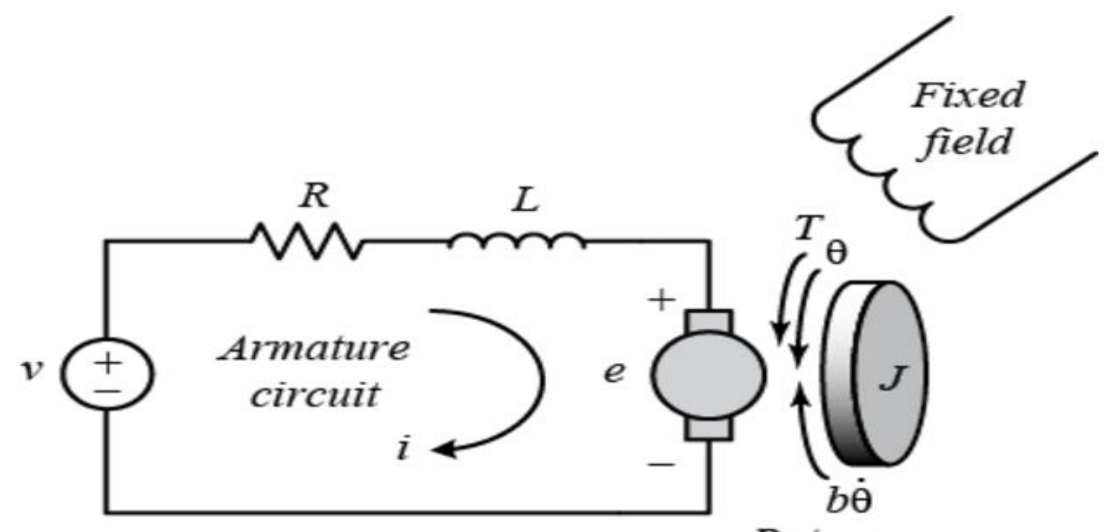

Rotor

Figure 1: DC Motor model.

The voltage represents the input signal and the speed represent the output. The system parameters of the system are explained in table 1 [6-8].

Table 1: system parameters[6-8].

\begin{tabular}{|c|l|c|l|}
\hline Symbol & \multicolumn{1}{|c|}{ Name } & Value & \multicolumn{1}{|c|}{ Unit } \\
\hline $\mathrm{J}$ & Rotor inertia & 0.01 & $\mathrm{~kg} \cdot \mathrm{m}^{\wedge} 2$ \\
\hline $\mathrm{B}$ & friction constant & 0.1 & N.m.s \\
\hline $\mathrm{Ke}$ & EMF constant & 0.01 & V/rad/sec \\
\hline $\mathrm{Kt}$ & torque constant & 0.01 & N.m/Amp \\
\hline $\mathrm{R}$ & resistance & 1 & Ohm \\
\hline L & inductance & 0.5 & $\mathrm{H}$ \\
\hline
\end{tabular}

The internal torque which formed is qualified to the current of the armature. The field is expected as a constant value for simplicity. The torque is proportional to constant factor $\left(\mathrm{K}_{\mathrm{t}}\right)$ Eq.(1):

$$
\mathrm{T}=\mathrm{K}_{\mathrm{t}} \mathrm{i}
$$

The electromotive force is qualified to angular velocity constant $\left(K_{e}\right)$.

$$
E=K_{e} \theta
$$

The constants of the torque \& EMF are equals, therefore, can put $\mathrm{K}$ constant to describe them both. From the figure 1 .

$$
J \ddot{\theta}+b \dot{\theta}=K \dot{\imath}
$$




$$
L \frac{d i}{d t}+R i=V-K \dot{\theta}
$$

The system is modeled by using Laplace transform to get the equations below:

$$
\begin{gathered}
s(J s+b) \Theta(s)=K I(s) \\
(L s+R) I(s)=V(s)-K \Theta(s)
\end{gathered}
$$

The transfer function is designed by eliminating the current value $\mathrm{I}(\mathrm{s})$ to get the transfer function produced by rotating speed and armature voltage.

$P(s)=\frac{\dot{\Theta}(s)}{V(s)}=\frac{K}{(J s+b)(L s+R)+K^{2}} \quad\left[\frac{\mathrm{rad} / \mathrm{sec}}{V}\right]$

In order to represent the system by state variable by choosing the speed and the current as the state variables. The input is The voltage and the output is the speed as shown in the equations.

$$
\begin{aligned}
& \frac{d}{d t}\left[\begin{array}{l}
\dot{\theta} \\
i
\end{array}\right]=\left[\begin{array}{cc}
-\frac{b}{J} & \frac{K}{J} \\
-\frac{K}{L} & -\frac{R}{L}
\end{array}\right]\left[\begin{array}{l}
\dot{\theta} \\
i
\end{array}\right]+\left[\begin{array}{c}
0 \\
\frac{1}{L}
\end{array}\right] V \\
& y=\left[\begin{array}{ll}
1 & 0
\end{array}\right]\left[\begin{array}{c}
\dot{\theta} \\
i
\end{array}\right]
\end{aligned}
$$

\section{PROPOSED CONTROLLER}

The FOPID algorithm is implemented to enhance the response by minimize the error signal between the input and the output signals. Generally the FOPID is govern by this equation [1, 9]:

where $\lambda$ and $\mu$

$$
G_{\mathrm{c}}(s)=K_{\rho}+\frac{K_{\mathrm{i}}}{S^{\lambda}}+K_{D} S^{\mu}
$$

represent gains, the old-style integer order PID controller $\lambda$ and $\mu$ are set to 1 if its needed to change to classical PID controller. Fast Genetic Algorithms (FGA) are stochastic international algorithm depends on the normal evolution to produce good solutions and solve the problems. GA generate initial populace of keys applying the standard of being of the fittest to yield improved keys [10]. FGA technique is used to overcome the problem in classical genetic algorithm by decreases time [11]. This algorithm is very simple for the implementation. FGA used to get the best five gains for the controller to convalesce the values. Best gains constants shaped when achieves the objective function which carries the greatest values. The chromosome contains 5 genes $(\mathrm{kp}, \mathrm{Ki}, \mathrm{Kd}, \lambda \& \mu)$ and the integral square error (ISE) criteria is used a fitness function in this implementation [10].

In this implementation the values of each parameter for genetic algorithm are illiterates bellow:

- $\quad$ The generation number will access to $=100$.

- $\quad$ The size of population $=20$. 


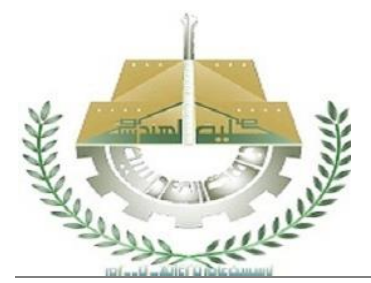

JOURNAL OF AL-QADISIYAH FOR

ENGINEERING SCIENCE

Vol. 10 , No. 4

ISSN: $1998-4456$

- Chromosome length should be five gens.

- The govern law to calculate fitness is:

$$
\operatorname{Fit}(y)=\frac{1}{\operatorname{ISE}+\varepsilon}
$$

The fitness is selected contingent difficult for the people which having high value to give good. The $\varepsilon$ is a unceasing unimportant about (0.0006) summed with ISE in the denominator of the equation 11 to evade the infinity. Figure 2 shows the chromosome with five genes.

\begin{tabular}{|l|l|l|l|l|}
\hline $\mathrm{K}_{\mathrm{p}}$ & $\mathrm{K}_{\mathrm{i}}$ & $\mathrm{K}$ & $\lambda$ & $\mu$ \\
\hline
\end{tabular}

Figure 2: Chromosome representation.

FGA is used to solve the problem based on the required values. Figure 3 shows the proposed algorithm to get optimum five genes required. 


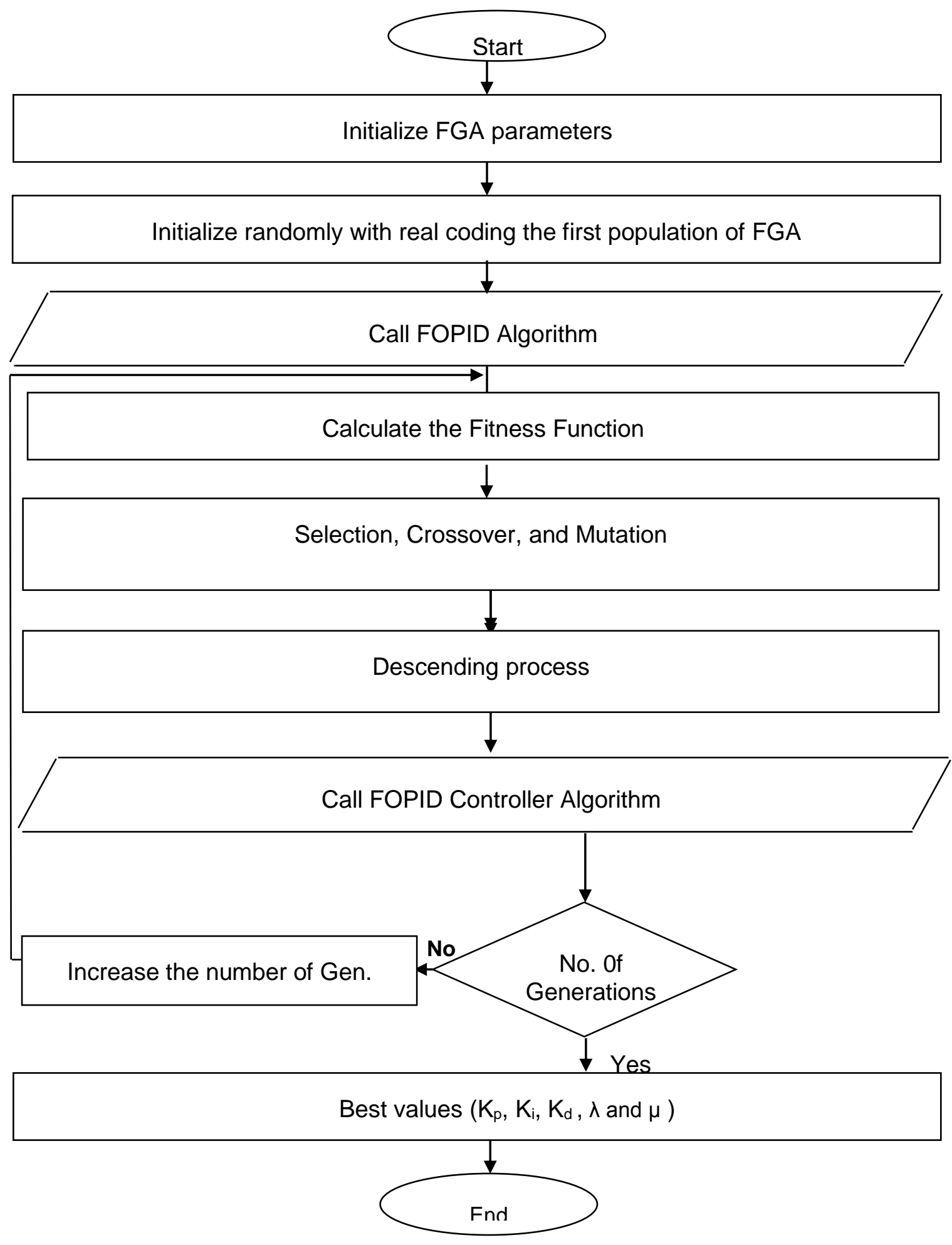

Figure 3: FGA-FOPID algorithm. 


\section{RESULTS}

The proposed work is tested by enhancement of the response of the DC motor system as shown in the simulation model in figure 4 based on MATLAB program.

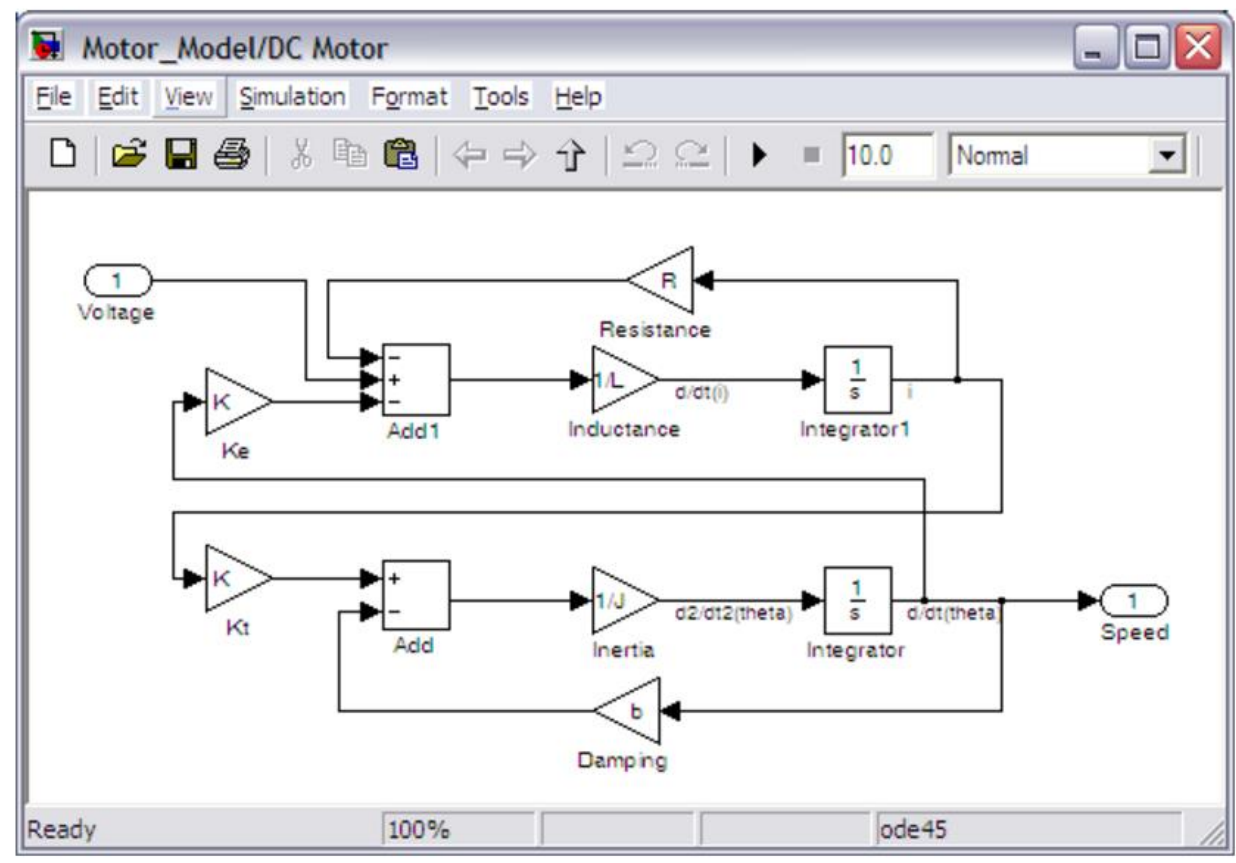

Figure 4: DC speed control model in MATLAB program.

The dynamic calculations are demonstrated in Eq. (12) and Eq.(13):

$s(J s+b) \Theta(s)=K I(s)$

$(L s+R) I(s)=V(s)-K s \Theta(s)$

$P(s)=\frac{\dot{\Theta}(s)}{V(s)}=\frac{K}{(J s+b)(L s+R)+K^{2}} \quad\left[\frac{\mathrm{rad} / \mathrm{sec}}{V}\right]$

The is constructed as shown in figure $\mathbf{5}$. 


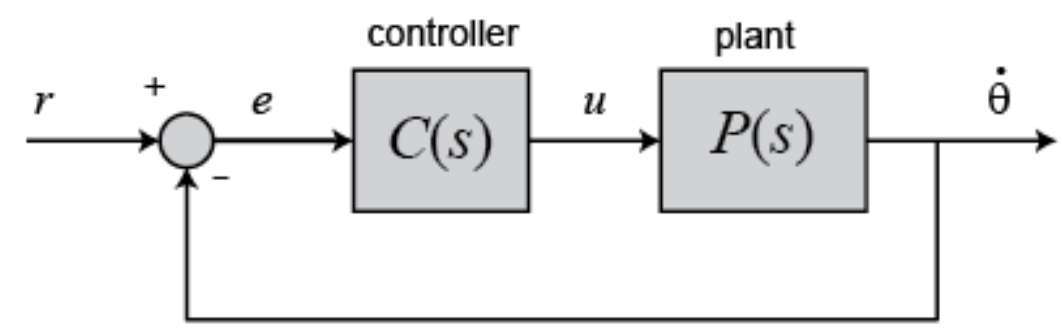

Figure 5: Control system.

The final response of the system with and without controller are illustrated in figure (6-9).

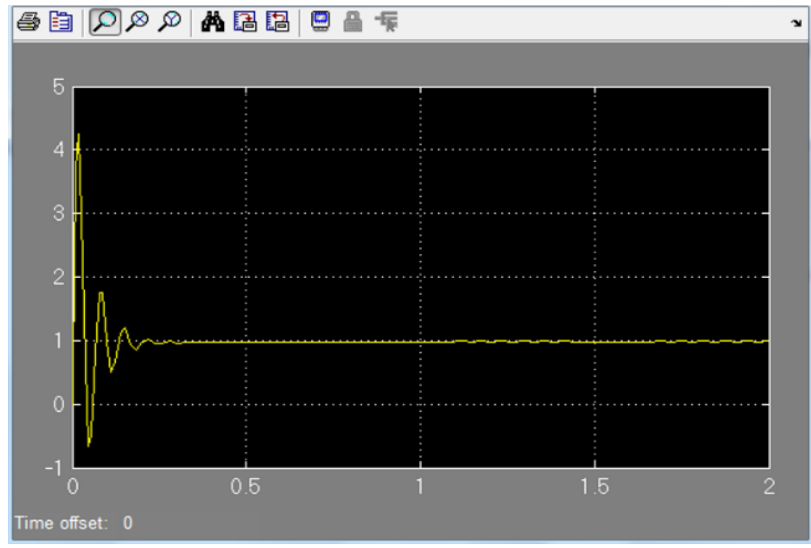

Figure 6: The response without controller.

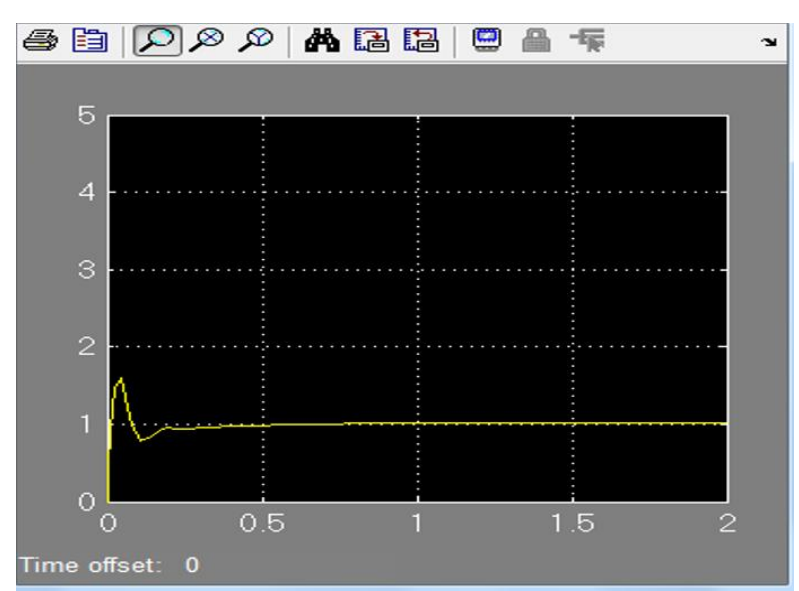

Figure 8: The response with FOPID.

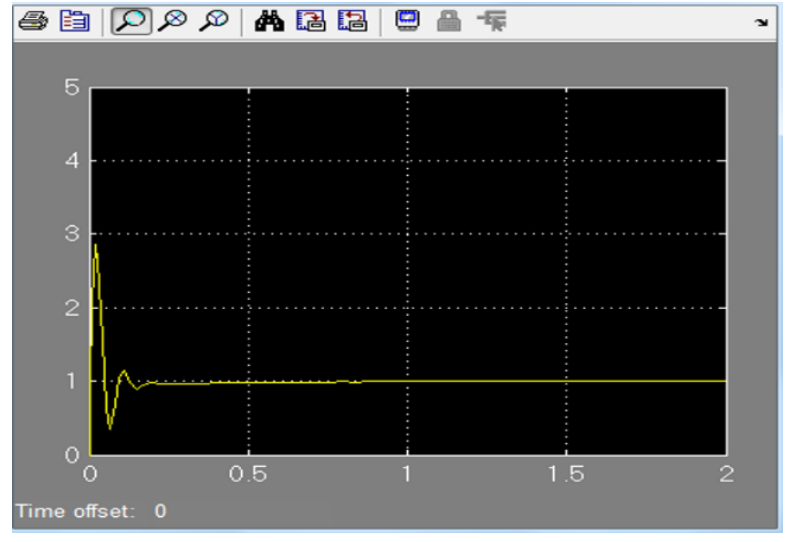

Figure 7: The response with PID.

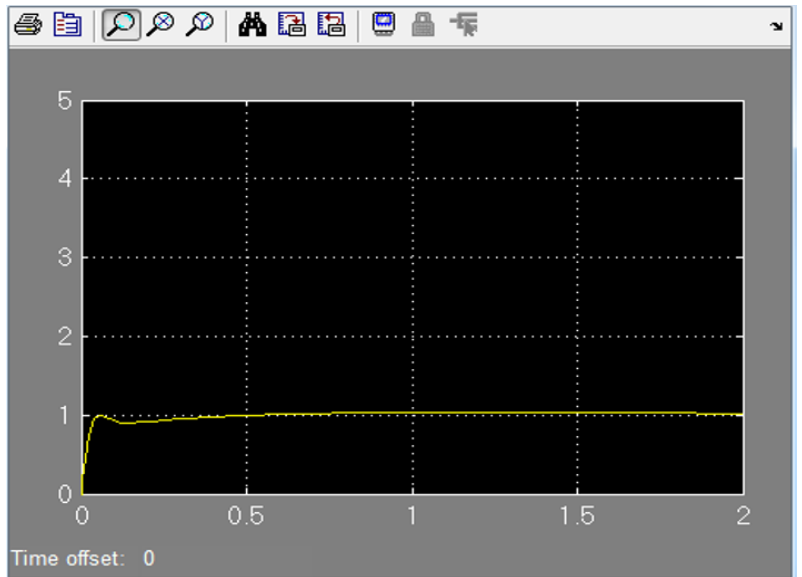

Figure 9: The response with FGA-FOPID. 


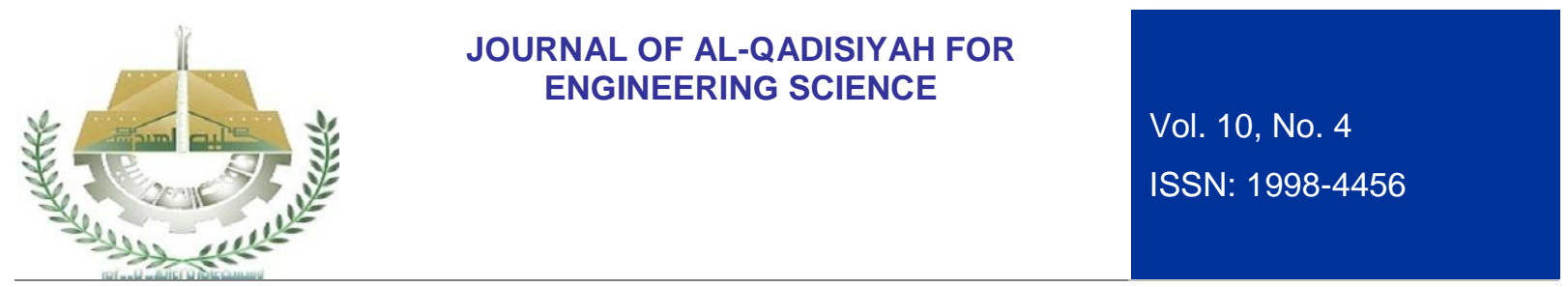

The performance of the system is illustrated in table 2.

Table 2: The Performance Indexes with different controllers.

\begin{tabular}{|c|c|c|c|c|c|}
\hline \multirow{2}{*}{ Type of Controller } & \multirow{2}{*}{ ISE } & \multicolumn{4}{|c|}{ Time response parameters } \\
\cline { 3 - 6 } & & tr & tp & $\mathbf{0 ~ . S ~}$ & tss \\
\hline Without controller & 29.194 & 0.25 & 0.25 & 3.31 & 0.82 \\
\hline PID & 3.112 & 0.21 & 0.21 & 1.82 & 0.71 \\
\hline FOPID & 2.924 & 0.27 & 0.22 & 0.51 & 1.2 \\
\hline FGA-FOPID & 1.8651 & 0.29 & 0.15 & 0.12 & 1.1 \\
\hline
\end{tabular}

From table 2, the overall response of the system is enhanced more by the proposed controller, the minimum ISE value is produced by the FGA-FOPID controller, which means that the best output response is obtained.

\section{CONCLUSIONS}

The suggested work which named FGA-FOPID is applied and tested in this paper by mixing FOPID and FGA. It is very good controller to improve the response of the DC motor compared with FOPID and conventional PID system. The proposed system overcome several difficulties by mixing FOPID with FGA. In the proposed work the fitness function is based on ISE and its very efficient choose. Any change in the parameter will gives effect on the behavior of the system. The gotten simulated results are encouraged to apply this controller on other system.

\section{REFERENCES}

1. Zhang, Y. and J. Li, Fractional-order PID Controller Tuning Based on Genetic Algorithm, in 2011 International Conference on Business Management and Electronic Information (BMEI) 2011: Guangzhou, China.

2. M, A.V.B., et al., Proposals for fractional-order PID tuning, in in the first IFAC symposium on Fractionalorder differentiation and its applications. 2004: Bordeaux, France, .

3. I, P., et al., Practical application of digital fractional-order controller to temperature control,, in 36th IEEE CDC. 1999: San Diego.

4. Mohammed, N.F., X. MA, and E.S., Tuning Of PID Controller For Diesel Engines Using Genetic Algorithm, in IEEE International Conference on Mechatronics and Automation (ICMA). 2013 Japan p. $1523-1527$.

5. Patrick Lanusse, et al., LTuning of an active suspension system using a fractional-order controller and a closed-loop tuning, in The 11th International Conference on Advanced Robotics. 2003. p. 258-263.

6. Tang, W.-J., Z.-T. Liu, and Q. Wang, DC Motor Speed Control Based on System Identification and PID Auto Tuning. in Proceedings of the 36th Chinese Control Conference July 26-28, 2017. Dalian, China.

7. Dorf, R.C. and R.M. Bishop, Modern Control Systems, ed. S. Edition. 1995: Addison-Wesley, Reading, Massachusetts.

8. Franklin, G.F., J.D. Powell, and A. Emani-Naeini, Feedback Control of Dynamic Systems. AddisonWesley, Reading, Massachusetts, ed. Third Edition. 1994.

9. M, A.V.B., et al., Proposals for fractional-order PID tuning in the first IFAC symposium on Fractional-order differentiation and its applications. 2004. Bordeaux, France. 
10. Mohammed, N.F., X. MA, and E. Song, Tuning Of PID Controller For Diesel Engines Using Genetic Algorithm. in 2013 IEEE International Conference on Mechatronics and Automation (ICMA). 2013. Japan IEEE.

11. kumar, B.R., et al., Short-range Fixed head Hydrothermal Scheduling using Fast Genetic Algorithm, in Industrial Electronics and Applications (ICIEA), 2012 7th IEEE Conference on. 2012, IEEE: Singapore. p. $1313-1318$. 